\title{
IDENTIFICAÇÃO DE OPORTUNIDADES EMPREENDEDORAS POR MULHERES
} IDENTIFICATION ENTREPRENEURIAL OPPORTUNITIES FOR WOMEN

Rony KlayViana de Freitas UFSE - Universidade Federal de Sergipe - SE ronyfreitas@gmail.com

Rivanda Meira Teixeira UFSE - Universidade Federal de Sergipe - SE rivandateixeira@gmail.com

Submissão: $22 / 06 / 2015$

Aprovação: 13/09/2016 


\title{
RESUMO
}

Este estudo procurou integrar dois temas relevantes para o estudo do empreendedorismo: identificação de oportunidades e gênero, e teve como objetivo analisar como ocorre o processo de identificação das oportunidades de criação de novos negócios na perspectiva de mulheres empreendedoras do estado de Sergipe. O estudo qualitativo teve como método a história oral. Foram ouvidas três empreendedoras das cidades de Aracaju e São Cristóvão do Estado de Sergipe, proprietárias de pequenos negócios. Os resultados indicaram que as experiências prévias das empreendedoras estão relacionadas com a oportunidade identificada e que estas possuem amplo conhecimento do serviço oferecido. Além disso, verificou-se a intensa participação da família das mulheres no processo de identificação das oportunidades, o que permitiu inferir que identificar uma oportunidade possa não ser um processo exclusivamente individual.

Palavras-chave: identificação de oportunidades; empreendedorismo feminino; pequenos negócios, processo empreendedor.

\begin{abstract}
This study sought to integrate two themes relevant to the study of entrepreneurship: identifying opportunities and gender and the purpose was analyze how occurs the process of identifying opportunities to create new business from the perspective of women entrepreneurs in the state of Sergipe. The qualitative study had as method as oral history. Were heard three enterprising cities of Aracaju and São Cristóvão in Sergipe State, owners of small businesses in the service sector. The results indicated that the previous experiences of entrepreneurs are related to the identified opportunity and that the entrepreneurs have extensive knowledge of the service offered. In addition, verified was the intense involvement of the family in the process of identifying opportunities, allowing inferring that identify an opportunity can would not be a uniquely individual process.
\end{abstract}

Keywords: opportunity identification; female entrepreneurship, small business, entrepreneurship process.

\section{INTRODUÇÃO}


O entendimento do fenômeno do empreendedorismo como um processo e não como um evento estático está, de certa forma, consolidado na literatura específica da área. Autores como Venkataraman (1997), Shane e Venkataraman (2000), Hisrich e Peters (2002), Baron e Shane (2007) definem o campo do empreendedorismo como a identificação, avaliação e exploração de oportunidades para criar bens e serviços futuros.

Nesse contexto, a pesquisa em empreendedorismo deve, precipuamente, demonstrar como determinados grupos de pessoas respondem a situações de oportunidade (SHANE; VENKATARAMAN, 2000; ARDICHVILI; CARDOZO; RAY, 2003). A identificação da oportunidade é apontada como aquilo que distingue o empreendedor das outras pessoas. Diante dessa consolidada constatação é surpreendente que ainda sejam poucas as publicações que tratem especificamente do tema (FILION; LIMA, 2009).

Em termos nacionais, as pesquisas de empreendedorismo são de fundamental importância, visto que em 2015, 52 milhões de brasileiros com idade entre 18 e 64 anos estavam envolvidos na criação ou manutenção de algum negócio, na condição de empreendedor em estágio inicial ou estabelecido. Quando avaliada a proporção de empreendedores motivados por oportunidade em relação ao total de empreendedores iniciais, observou-se, em 2015, uma alteração em relação aos anos de 2012 a 2014. Enquanto nesses três anos a proporção manteve-se próxima dos 70\%, em 2015 ocorreu uma significativa redução, chegando a 56,5\%. (GEM, 2015).

No entanto quando se examina os dados publicados pelo GEM 2015 com foco no gênero observa-se que a proporção de mulheres que abriu seu negócio por oportunidade (45\%) foi bem inferior à encontrada na média do total de empreendedores no país (56\%) e à encontrada no grupo dos homens (67\%). Aparentemente, conforme explica esse relatório, a queda do empreendedorismo feminino "por oportunidade" se deve à desaceleração da economia e a um ingresso mais forte de mulheres no mercado de trabalho, mulheres que não estavam nesse mercado (não estavam ocupadas nem desocupadas), mas que optaram pelo ingresso no mesmo para complementar a renda familiar, nesse momento de crise. Dado que a população feminina é a que, tradicionalmente, apresenta o menor grau de inserção no mercado de trabalho, o ingresso desse novo contingente de pessoas no mercado de trabalho parece ter sido composto com forte participação feminina. Esse processo, concomitante à redução do número de vagas no mercado de trabalho, ajuda a explicar o forte aumento da proporção de empreendedoras por necessidade em 2015(GEM-2015). 
Ainda examinando esse relatório com foco no gênero, observa-se que mulheres são mais jovens (mais de $40 \%$ das empreendedoras têm até 34 anos, enquanto no grupo dos homens $50 \%$ estão entre 35 e 54 anos); são mais escolarizadas (32\% dos homens tem no máximo o primeiro grau incompleto, esta proporção cai para $29 \%$ no grupo das mulheres); e ganham menos (69\% recebem até 3 S.M. contra 49\% nos homens). Comparado aos homens, as mulheres afirmam operar com produtos mais novos, com menos concorrentes, mais tradicionais, mais dependente do mercado interno (poucos clientes no exterior), com poucos ou nenhum empregado (conta-própria), com menor expectativa de criação de novos empregos e com faturamento menor. (GEM-2015)

Por todo o exposto, este estudo torna-se relevante para a compreensão de duas temáticas: a identificação de oportunidades empreendedoras e o empreendedorismo feminino. Utilizou-se uma abordagem qualitativa, com base na metodologia da história oral. Foram ouvidas três mulheres empreendedoras sergipanas proprietárias de pequenos negócios. Para Gomes e Santana (2010) os relatos e experiências empresariais têm se tornado um importante tópico para o entendimento das organizações.

Este estudo teve como objetivo principal analisar o processo de identificação de oportunidades empreendedoras por mulheres sergipanas. Especificamente buscou delinear o perfil das mulheres empreendedoras e dos negócios criados por elas; identificar as fontes de oportunidades utilizadas pelas empreendedoras sergipanas para criação de seus negócios; verificar o conhecimento e as informações prévias sobre o mercado ao qual o negócio foi criado; e, por fim, apontaras formas de identificação da oportunidade que originaram os seus negócios.

\section{IDENTIFICAÇÃO DE OPORTUNIDADES EMPREENDEDORAS}

A identificação de uma oportunidade é o ponto principal do processo de empreendedorismo (KIZNER, 1973; VENKATARAMAN, 1997; SHANE; VENKATARAMAN, 2000; BARON; SHANE, 2007; GREGOIRE; SHEPHERD, 2012). Portanto, a investigação sobre ação empreendedora deve focar em fatores que explicam porque indivíduos são mais capazes de identificar e explorar oportunidades promissoras que outros (GRUBER; MACMILLAN; THOMPSON, 2013).

As oportunidades variam quanto à sua fonte. Fatores como mudanças na tecnologia atual e o surgimento de novas tecnologias (CHA; BAE, 2010), demanda de mercado não 
atendida (ANOKHIN, WINCENT; AUTIO, 2011), recursos subutilizados, mudanças políticas e regulatórias, mudanças de hábitos de consumo, necessidades dos clientes, apoio de órgãos de fomento (EKHARDT; SHANE, 2003), dentre outros, geram novas informações sobre como os recursos podem ser usados de forma diferenciada.

Na visão de Baron e Shane (2007) algumas pessoas estão mais aptas do que outras a identificarem oportunidades, porque tem melhor acesso a determinados tipos de informação e são capazes de utilizar essa informação tão logo as tenham. Nesse contexto, os empreendedores usam informações para criar produtos ou serviços e vendê-los com vistas ao lucro empresarial (SHANE; VENKATARAMAN, 2000; GRUBER; MACMILLAN; THOMPSON, 2013).

Mudanças nas demografias sociais também geram oportunidades (DRUCKER, 1985). O conhecimento do setor do novo negócio é outro fator que pode ajudar a determinar os tipos e volume de oportunidades disponíveis para a identificação e exploração (ECKHARDT; SHANE, 2003; SHORT et al, 2010). Shook, Priem e McGee (2003) destacam que a posse de informações e o conhecimento do setor podem permitir que algumas pessoas, mesmo que não estejam ativamente à procura de oportunidades, vejam particularidades de oportunidades que outros não conseguem perceber.

Shane (2000) mostra que existem três tipos de capital humano específico que impactam a capacidade de identificar oportunidades: o conhecimento prévio do mercado; o conhecimento prévio de maneiras para atender os mercados; e, o conhecimento prévio dos problemas dos clientes. Esses três tipos de capital humano possibilitam à identificação de um maior número de oportunidades. Afirma ainda o referido autor que qualquer empreendedor vai descobrir somente aquelas oportunidades relacionadas com o seu conhecimento prévio, pois é de acordo com o conhecimento prévio que o indivíduo dará (ou não) valor a nova informação.

Nessa mesma linha de pensamento, Gregóire e Shepherd (2012) afirmam que quanto menor conhecimento cognitivo, menor será a crença que a oportunidade trará retorno positivo. Nesse sentido, teóricos cognitivos sugerem que os empreendedores experientes podem alavancar sua experiência prévia e conhecimento para processar a informação de forma mais eficiente (UCBASARAN; WESTHEAD; WRIGHT, 2009). Além disso, segundo esses autores, os empresários que podem processar informações de forma eficiente geralmente têm mais recursos cognitivos à sua disposição, o que pode permitir que eles valorem mais rapidamente e qualitativamente as informações. 
Porém até mesmo os indivíduos mais qualificados e experientes podem não identificar boas oportunidades (DIMOV, 2010). Ardichvili, Cardozo e Ray (2003) acreditam que esse fato acontece devido à heterogeneidade na sensibilidade das pessoas para criação e fornecimento de um novo valor.

Chandler, Lyon, e Detienne (2005) mostram que as diferenças entre indivíduos relacionados ao capital humano estão relacionadas com a seleção e aplicação de diferentes formas de identificação de oportunidade. Os autores identificaram os seguintes quatro processos de identificação de oportunidades:

No primeiro processo, Aprender $\rightarrow$ Replicar, a sequência começa com um indivíduo, trabalhando em uma indústria/empresa. Nesse ínterim, o indivíduo identifica uma demanda do mercado não atendida, replica e entrega o produto/serviço para um mercado carente. $\mathrm{O}$ processo Aprender $\rightarrow$ Replicar também pode ser realizado com pessoas que não estão inseridas no mercado de trabalho. A segunda forma, Aprender $\rightarrow$ Inovar, sugere que um indivíduo, trabalhando em uma indústria/empresa, identifica a necessidade do cliente, que não está sendo adequadamente atendida pela empresa e desenvolve um produto/serviço que representa uma inovação significativa para o que existe atualmente no mercado em uma nova empresa. Outra forma de identificação de oportunidades é por meio do processo Aprender $\rightarrow$ Adquirir, neste caso, a sequiência começa com um indivíduo que identifica um conceito de negócio de sucesso e leva vantagem de possuir renda disponível e oportunidades de fluxo de caixa para adquirir o negócio através de spin-offs, aquisições, e/ou acordos de licenciamento. No último caso, Inovar/Educar, o fluxo do processo começa quando um indivíduo criativo desenvolve um novo produto ou serviço, e em seguida, educa os clientes potenciais sobre os benefícios que o produto oferece, a partir daí cria-se um novo negócio.

Ardichvili, Cardozo e Ray (2003), definem que determinados indivíduos tem uma propensão a prestarem "mais atenção" a mudanças e oportunidades. Essa propensão é definida como alerta empresarial. O nível do alerta empresarial é provável que seja maior quando há uma coincidência de vários fatores: certos traços de personalidade, prévio conhecimento e experiência, e um grande rede de laços sociais. Os autores asseveram ainda que, quanto maior o número de eventos de identificação de oportunidades bem-sucedidos, maior a probabilidade de sucesso futuro na identificação de outros eventos de oportunidade.

Estudos recentes examinam como as diferenças individuais ou a personalidade criativa dos empreendedores podem influenciar a descoberta de oportunidades. Wood, McKelvie e Haynie (2014) em seu estudo apontam que diferenças individuais como motivação para a 
tarefa e fracassos anteriores são fatores determinantes na formação da descoberta de oportunidades. Os pequisadores verificaram que empresários que estão altamente motivados para avaliar oportunidades são mais fortemente influenciados por sinais de oportunidade positivos e menos influenciados por sinais de oportunidade negativos. Identificam que aqueles que já fracassaram são mais conservadores na percepção de oportunidades positivas. Igualemnete aqueles com alto receio de fracasso são geralemente menos atraídos por oportunidades e reage mais negativamente quando essas mesmas condições parecem ser desfavoráveis.

Por sua vez Shane e Nicolau (2015) pesquisaram que pessoas com personalidade mais criativa são mais prováveis do que outras de reconhecer oportunidades empreendedoras e iniciar negócios. Esse estudotTambém identificou que fatores genéticos são reponsáveis por parte da correlação positiva entre presonalidade criativa e comportamento emprendedor. Argumentam esses autores que outras pesquisas mostram que a criatividade é influencida pela situação, contexto e fatores coginitivos assim como por fatores individuais relacionados a personalidade. No entanto os resultados encontrados nesa pesquisa são complementares aos de outros enfoques para analisar o papel da criatividadee em empreendedorismo, incluindo aqueles que mostram que o aprendizado e as estruturas coginitivas afetam a criatividade ou o reconhecimento de oportunidades.

No Brasil vale destacar estudo recente de Albuquerque e Teixeira (2016) cujo objetivo foi analisar o processo de identificação e de exploração de oportunidade empreendedora com base no Modelo de Aprendizagem Organizacional 4i de Crossan, Lane e White. As evidências mostram que os empreendedores passaram pelo estágio de intuição, no qual a identificação de oportunidade se inicia com a idealização do negócio. Na fase de interpretação, a oportunidade se desenvolveu na rede informal dos empreendedores, especificamente com a família. Na fase de integração, a relação com a rede formal é essencial para a exploração da oportunidade. Por fim, a institucionalização ocorre quando a oportunidade é explorada, por meio das rotinas e dos processos internos, bem como do planejamento de expansão do negócio.

\section{EMPREENDEDORISMO FEMININO}

A inserção das mulheres no mercado desencadeou a abertura de pequenas empresas, que se tornaram o ponto de entrada mais "fácil” para participação no mercado de trabalho. Esse fato possibilitou às mulheres que queriam (querem) conciliar compromissos de trabalho 
e cuidado com a família. Birley (1989) destaca que desde então, as mulheres estão começando a se sentir mais confiantes sobre suas próprias habilidades, na construir suas próprias redes comerciais, para estabelecer a credibilidade com os clientes e fornecedores, e para começar sua vida empresarial. Todavia, conforme analisa Smith (2010) a noção de empreendedorismo ainda é ideologicamente enviesada para o mundo masculino.

Entrementes, no ambiente das micro e pequenas empresas brasileiras, é muito relevante a presença das empresas criadas e lideradas por mulheres (JONATHAN, 2005). Ainda segunda a autora, as mulheres não apenas constroem para si uma alternativa de inclusão ou permanência no mercado de trabalho, mas também geram empregos e promovem inovação e riqueza, contribuindo para o desenvolvimento socioeconômico do país. Gomes (2005), por sua vez, destaca que as mulheres estão mais presentes no mercado de trabalho na condição de empreendedora, e, cada vez mais se quer entender este fenômeno tendo em vista sua relevância econômica.

Todavia, Menzies, Diochon e Gasse (2004) relatam que ainda existem muitos mitos a respeito da mulher empreendedora, o que acaba criando estereótipos deturpados com potencial para degradar a imagem da mulher no tocante à sua capacidade gerencial, trazendo obstáculos para a atividade empreendedora. Jonathan (2005) aponta que as empreendedoras são bastantes assertivas ao lidar com a sua condição feminina, porém a quebra destes estereótipos e preconceitos envolvendo-as como proprietárias de negócios próprios é um processo em andamento.

Nesse contexto, Bardwick (1984) afirma que "as mulheres não são melhores nem piores que os homens. Não são completamente diferentes deles, nem totalmente iguais". Birley (1989) reforça essa ideia ao afirmar que os empreendedores do sexo feminino são semelhantes em muitos aspectos aos empreendedores do sexo masculino. Por esse motivo, ao analisar a inserção das mulheres como empreendedoras, é interessante considerar outras características especificas à conduta empresarial feminina.

Um dos fatores comuns na análise de histórias de vida de empreendedoras é a existência de modelos empreendedores na família, principalmente entre os pais ou pessoas mais próximas. Este é um dos determinantes do papel empreendedor, pois no processo de identificação desenvolvido com essas pessoas há um aprendizado cognitivo, afetivamente construído, que resulta na assimilação e na reprodução do modelo e, neste caso, o modelo empreendedor (MACHADO et al, 2003). 
Quanto a suas características psicológicas e comportamentais, as mulheres empreendedoras são descritas como persistentes, com alto desejo de realização e independência, ativas, persuasivas, inovadoras, precisas e adaptáveis às mudanças, e acreditam ainda que seu destino seja fruto de suas ações (MACHADO, 1999). Afirma ainda a autora que em termos de características gerais, algumas semelhanças são encontradas em diversos estudos, conduzindo às seguintes generalizações sobre a mulher empreendedora: a faixa etária predominante entre 31 a 50 anos de idade; bom nível educacional, pouco conhecimento de habilidades gerenciais; predomínio de primogênitas ou filhas únicas, predomínio de pais empreendedores, que teriam servido de modelo de identificação para essas empreendedoras.

Machado et al (2003) afirmam que existem outros fatores, tal como a trajetória profissional anterior, que são importantes para uma análise mais abrangente do processo de criação de empresas por mulheres que contribuem para esclarecer a tendência de que empresas iniciadas e dirigidas por mulheres sejam pequenas. Segundo as autoras, apesar de a maioria das mulheres que criam negócios serem empregadas em outras empresas anteriormente, a falta de perspectiva na carreira não é o principal motivo apontado por elas para a abertura das empresas.

A produção científica do empreendedorismo feminino tem sido objeto de estudos recentes e levantam as questões centrais que têm sido abordadas nas pesquisas realizadas com essa temática. Um dos estudos de maior destaque é o Ahl (2006) que foi realizado com a análise de discurso em 81 artigos sobre mulheres empreendedoras publicados nos quatro periódicos mas relevantes de empreendedorismo entre os anos 1882 e 2000. Os artigos revisados cobrem temas diversos como a psicologia das mulheres que empreendem, as suas experiências prévias, as atitudes, intenções de começar negócios, práticas gerencias, estratégias, redes sociais, questões relacionadas a família, acesso ao capital financeiro e desempenho de negócios criados por essas empreendedoras. A autora sugere novas direções para a pesquisa, para que não se limitem a reproduzir a subordinação feminina, mas que capturem mais fatores, identifique novas contingencias e faça comparações.

O estudo seminal de Jennings e Brush (2013) faz levantamento extensivo das pesquisas realizadas sobre mulheres empreendedoras, compara com a literatura em empreendedorismo em geral e discute os desafios e oportunidades de pesquisas na área. Aponta que o primeiro estudo publicado em periódico sobre mulheres empreendedoras data de 1976 e que em 2009 é criado o primeiro periódico especializado. Levanta quatro questões 
centrais na pesquisa sobre mulheres empreendedoras: 1) se homens e mulheres são igualmente propensos a empreender; 2) se existem diferenças com relação a busca de recursos financeiros, 3) se homens e mulheres adotam estratégias, práticas organizacionais e de gestão de forma distinta; 4) se empresas lideradas por mulheres tem a mesmo desempenho de empresas lideradas por homens? Apesar de resultados inconclusivos de muitas pesquisas para a questão 1 a resposta é não, de fato as mulheres são menos propensas do que homens a se envolverem nas diversas formas da atividade empreendedora. Para a questão 2 a resposta é primariamente sim, ou seja, em geral, negócios criado por mulheres tendem a ser financiados de forma diferente do os dos homens. Já para a para a questão 3 a resposta é sim e não pois embora existam diferenças notáveis com respeito a estratégia poucas diferenças foram encontradas nos estudos com relação as práticas organizacionais ou gerenciais. Finalmente, quanto a questão 4, a resposta é basicamente não, os negócios chefiados por mulheres não têm resultados tão bons quanto os chefiados por homens. As pesquisadoras concluem que empreendedorismo é um fenômeno de gênero e que o empreendedorismo é intrinsicamente relacionado a famílias, pode ser por resultando por necessidade e por oportunidade e que empreendedores buscam objetivos que vão além de ganhos econômicos.

No Brasil vale destacar a revisão da produção científica sobre empreendedorismo feminino realizado por Gomes et al 2014. Foram avaliadas pesquisas publicadas em periódicos brasileiros e internacionais a partir da década de 1970. Como resultado verificou que os estudos foram de natureza quantitativa e voltam-se para traçar o perfil das mulheres. Essa tentativa gerou muitos estudos que buscaram apontar diferenças entre homens e mulheres por meio de dados demográficos, familiares, ocupacionais e educacionais. A maior parte dos trabalhos se limitou a descrever pequenos segmentos da população de mulheres empreendedoras e não avançaram na aplicação e desenvolvimento de teorias. Poucos foram os estudos que elaboraram uma análise teórica especificamente sobre a temática "gênero".

\section{IDENTIFICAÇÃO DE OPORTUNIDADES POR MULHERES}

Apesar do discurso de igualdade de condições e oportunidades há evidencias de que existem desigualdades na participação masculina e feminina no contexto empresarial, seja em relação aos níveis salariais, possibilidade de crescimento na carreira ou na criação e condução de novos negócios. (CRAMER et al, 2012). As diferenças de gênero sugerem ainda que as mulheres e os homens podem diferir significativamente na forma de identificação de 
oportunidade (DETIENNE; CHANDLER, 2007). O relatório sobre Gênero, Educação, Emprego e Empreendedorismo da Organização para a Cooperação e Desenvolvimento Econômico (OECD) de 2012, concluiu que as mulheres, em regra, são menos ansiosas do que os homens no momento de iniciar seu próprio negócio.

Ainda segundo o relatório da OECD (2012), as mulheres, geralmente, utilizam diversas fontes de oportunidades para começar um negócio, diferentemente dos homens, que geralmente, utilizam uma menor quantidade de fontes. As mulheres também tendem a dar mais importância à flexibilidade do trabalho. Em média, as proprietários de negócio têm níveis mais elevados de escolaridade, entretanto, com menos experiência gestão de um negócio.

No entanto, não existe correlação significativa entre o nível de educação das mulheres e da sua atividade empresarial. Isto sugere que não é o nível, mas, o tipo do investimento na educação das mulheres, que importa para o a identificação de oportunidades empreendedoras.

Para Ibarra (1997) os laços fortes (pessoas próximas) são, muitas vezes, responsáveis pela limitação de descoberta de oportunidades empreendedoras por mulheres, visto que, possuir uma rede de relacionamentos ampla e diversificada facilita o processo de identificação de oportunidades. As mulheres são, para Rutashobya, Allan e Nilson (2009), em geral, mais dispostas a manter muitos laços familiares e poucos laços não familiares, enquanto os homens são mais dispostos a formar mais laços fora da família. Yetim (2008) reforça essa ideia ao afirmar que as empreendedoras constroem relacionamentos confiáveis com suas fontes diretas de contato: familiares, parentes e amigos. Para a autora, esse fato apontado, também é um limitador para identificar novas oportunidades de negócio.

Nesse contexto, Vale, Serafim e Teodósio (2011), em estudo a cerca da utilização de redes sociais na criação de empreendimentos, sugerem que as mulheres confiam, relativamente mais, em fontes de informações que se encontram mais próximas a elas. As mulheres parecem mostrar-se mais sensíveis à influência de terceiros - em geral homens tanto no que diz respeito à decisão de criar uma empresa, quanto na gestão do dia a dia da empresa que trabalham. Os autores ainda relatam que o acesso de uma empreendedora a certos tipos de oportunidade seria canalizado e viabilizado através de suas redes de relacionamentos.

Detienne e Chandler (2007) concluíram em estudo que explora as diferenças de gênero na identificação de oportunidade, que o número de empregos anteriores e experiência no setor de varejo previu positivamente para o número de oportunidades identificadas pelas mulheres. 
Mais especificamente, González-Álvarez e Solís-Rodríguez (2011), destacam que os homens descobrem mais oportunidades empresariais do que as mulheres. Detienne e Chandler (2007), acrescenta ainda que mulheres e homens utilizam diferentes tipos de capital humano para identificar oportunidades.

Machado et al (2003) ao analisar a criação de empresas por mulheres, concluiu que existe uma relação entre a experiência anterior e o ramo escolhido. As mulheres geralmente identificam oportunidades no mesmo ramo em que atuavam anteriormente. De acordo com esses autores, geralmente, os fatores antecedentes ao processo de criação das empresas, observa-se que a maioria das empreendedoras teve pais e mães empreendedores; a experiência anterior foi o fator antecedente mais relacionado com o ramo de atividade escolhido para o novo negócio; e, área de formação escolar teve correspondência com a atividade da empresa. Outro fato importante é que as mulheres tem mais probabilidade que os homens de apresentar algum diferencial (inovação) na criação de seus negócios em relação a empresa que atuava (DETIENNE; CHANDLER, 2007).

Estudo recentes analisam o empreendedorismo feminino e a descoberta de oportunidades de negócios sob diferentes perspectivas teóricas, o dos estereótipos e da identidade. A pesquisa realizada por Gupta, Gotkane Gunay (2014) baseia-se na teoria da ameaça do estereótipo para explorar as diferenças entre homens e mulheres na avaliação de novas oportunidades de negócios. Foram realizados dois experimentos controlados, um com estudantes de negócios na Turquia e outro com profissionais nos Estados Unidos. Os participantes foram aleatoriamente designados para condições experimentais específicas e sua avaliação de uma nova oportunidade de negócio foi medida após a apresentação de informações estereotipadas. Como previsto, os homens relataram maior avaliação de oportunidade do que as mulheres quando não são apresentadas informações de genero estereotipadas, ao passo que os homens e mulheres avaliaram as oportunidades de negócio igualmente favoráveis quando os empreendedores foram descritos usando atibutos de neutralidade de genero. Curiosamente, as diferenças de gênero na avaliação de oportunidade foram exacerbadas quando o empreendedorismo estava relacionado informação estereotipada masculino, e revertido em favor das mulheres quando empreendedorismo estava ligada à informações estereotipadas feminina.

Em estudo qualitativo realizado sobre oportunidades e gênero Lewis et al (2016) analisaram oito empreendedoras mães tentando compreender o papel da identidade na descoberta, desenvolvimento e exploração de oportunidades e como a transição essas 
identidades podem mobilizar ou limitar mulheres empreendedoras. Os resultados permitem identificar como conflitos de identidade, congruência de papeis e criação de identidade recíproca tem papel crítico na criação e negócios como forma de empreendedorismo. Baseado no constructo de identidade, auto verificação e aprovação de identidade os autores elaboram um quadro teórico para compreender as transições de identidade em relação a comportamentos na identificação de oportunidades.

\section{ASPECTOS METODOLÓGICOS}

O presente estudo é qualitativo e está baseado na perspectiva fenomenológica, visto que retrata a realidade a partir das experiências subjetivas das participantes da pesquisa. Creswell (2003) complementa que tal abordagem inclui o estudo de problemas relacionados a adentrar o campo de percepção dos participantes, vendo como eles experimentam, vivem e expõem o fenômeno, à procura do significado das experiências para os participantes. Para a fenomenologia, explica Faria (2009), não interessa tanto como os fatos se mostram, mas qual o significado dos mesmos. O sentido não está no fenômeno, mas na atribuição que o sujeito lhe dá, a partir da significação conferida pela razão.

Nesta pesquisa a preocupação foi interpretar os fatos, a partir das experiências e visões pelas empreendedoras pesquisadas. O estudo percorreu um caminho metodológico que possibilitou a captação das singularidades da vivência de cada mulher empreendedora sergipana na busca de oportunidades, pois, de acordo com Faria (2009), o fenômeno se mostra ao sujeito, mas não como ele é e sim de acordo com o sentido que lhe atribui o sujeito.

Foi utilizado o método da história oral (ALBERTI, 1989; FERREIRA; AMADO, 1998; ALBERTI, 2004; FREITAS, 2006). A escolha desse método baseou-se na possibilidade de coletar informações por meio da versão dos indivíduos que protagonizaram um evento e permite a "recuperação do vivido, conforme concebido por quem viveu" (ALBERTI, 1989). Esse método permite ainda captar as experiências elaboradas por indivíduos pertencentes a categorias sociais cujas percepções e intervenções geralmente são excluídas da história e documentação oficiais das organizações. Assim, é possível registrar sua visão de mundo, suas aspirações e utopias e, consequentemente, aquelas do grupo social ao qual pertencem (GOMES; SANTANA,2010).

A história oral pode ser dividida em três gêneros distintos: tradição oral, história de vida e história oral temática (MEIHY, 2002; FREITAS, 2006). Essa pesquisa adotou a 
história oral temática, pois foram realizadas entrevistas com um grupo de pessoas sobre um assunto específico (ALBERTI, 1989) e as perguntas concentraram-se apenas em um período de suas vidas (FREITAS, 2006).

Foram ouvidas 03 (três) empreendedoras das cidades de São Cristóvão e Aracaju, no Estado de Sergipe. Alberti (2004) afirma que na história oral a escolha dos participantes da pesquisa não deve estar orientada por critérios quantitativos ou preocupação com amostragem, mas a partir da representatividade e do significado da experiência dos sujeitos. Além do critério de representatividade, as participantes foram selecionadas pelos critérios de acessibilidade, e da tipicidade - indivíduos que os pesquisadores consideraram representativos do grupo para garantir a diversidade entre os entrevistados (VERGARA, 2006).

Os dados foram coletados através de entrevista semiestruturada em profundidade, adequada para captar ações realizadas no passado. Após a transcrição das entrevistas, o relato foi devolvido às participantes para serem revistas e validadas (FERREIRA; AMADO, 1998) e ainda, pela necessidade de aprofundar outros aspectos significativos para o objeto da pesquisa (DEMARTINI, 1988). O retorno das entrevistas às participantes, também representa um critério de validade, que em consonância com Creswell (2003) é utilizada para sugerir se as descobertas estão em conformidade com o ponto de vista do pesquisador e do participante.

\section{RESULTADOS DO ESTUDO}

Nesta seção são apresentados os relatos das 03 (três) empreendedoras que participaram da pesquisa: E1, E2 e E3. Os relatos revelam experiências e fatos vividos por elas na identificação de oportunidade de criação dos seus negócios.

\section{A Empreendedora E1}

E1, 28 anos, solteira, natural de Aracaju/SE, não tem filhos. A empreendedora é formada em Administração. O seu pai desde muito cedo é comerciante. E1 conta que seu pai nunca teve outra profissão, sempre esteve envolvido no mundo dos negócios. Sua mãe trabalhou por pouco tempo na iniciativa privada, mas devido à visão empreendedora que possui, abriu seu próprio negócio. Machado (1999) afirma que há o predomínio de pais empreendedores, que servem de modelo de identificação para as empreendedoras. Nesse 
contexto, a convivência de E1com os pais na empresa da família foi a principal influência para abrir sua própria empresa.

Estar em contato com o comércio foi também fator determinante para a opção pelo curso de administração. A escolha da formação acadêmica foi justamente em função de sua decisão profissional pelo empreendedorismo. A depoente relata que a sua experiência profissional foi aperfeiçoada com o curso superior. Ademais, o empreendimento dos pais proporcionou a oportunidade de aprendizado prático desde a sua infância. Conforme a empreendedora explica:

"eu ficava na parte administrativa do comércio, na realidade era um verdadeiro faz tudo, por ser uma empresa familiar, você já sabe como é. Eu nunca tive outra experiência profissional, apenas o trabalho na empresa da família e posteriormente em minha própria empresa, nunca trabalhei para ninguém"

Verifica-se, que a depoente apresenta uma característica comum as mulheres empreendedoras, segundo Machado (1999), Hisrich e Peters (2002): a satisfação de verificar os frutos do seu trabalho sob o seu domínio.

$\mathrm{Na}$ visão de Birley (1989), o empreendedorismo proporcionou uma maior oportunidade para a flexibilidade necessária na vida da mulher, um estilo de vida que combinava tanto responsabilidades domésticas e de emprego. Esse pensamento pode ser comprovado na fala da empreendedora:

"eu sempre gostei muito de comércio, o fator mais interessante é não ter horário de
chegada nem saída, poder ter tempo para minhas outras obrigações pessoais. Outro
fato é ter para mim toda a responsabilidade, é o que sempre quis, me sinto
extremamente satisfeita, mesmo nas horas de muito cansaço, estresse, sabendo que
não tenho férias. E tem mais, mesmo se eu gostasse de trabalhar para outras
pessoas, acredito na dificuldade de encontrar um emprego que a remunere na
mesma proporção"

Ferreira e Nogueira (2013) argumentam que a família interfere na dinâmica dos negócios assim como os mesmos negócios estão presentes em seus lares. Esse fato acontece desde a identificação da oportunidade. A empreendedora afirma que a ideia de abrir um restaurante foi corroborada por sua mãe, que foi a grande responsável pela montagem do negócio e também com o apoio do pai. E1 alega que não teve contato com outras pessoas, que as decisões foram tomadas no seu seio familiar.

A empreendedora conta que o ramo escolhido "foi um tiro no escuro", pois não possuía experiência e levou muito tempo até que conseguisse clientes. A escolha por 
restaurante, e não por outro ramo, deu-se pela falta de um serviço self service na cidade, constatado através de um levantamento informal, conforme relata a empreendedora:

"minha mãe fez um levantamento do que estava precisando na cidade e viu que não tinha um restaurante mais arrumadinho, comida a quilo, e foi o primeiro e até hoje o único que trabalha com comida a quilo. Então por isso que nós achamos interessante o restaurante, também tinha uma demanda que não era atendida, a experiência que tínhamos era pessoal, pois sempre gostei de cozinhar, eu gosto muito desse negócio de comida, mas, hoje em dia, no restaurante eu só faço auxiliar, mas o foco mesmo do restaurante é porque não tinha na cidade"

Verifica-se que a empreendedora se baseou na identificação de uma demanda não atendida, fato destacado por Anokhin, Wincent e Autio (2011) como uma valiosa fonte de oportunidade. A empreendedora percebeu a mudança no cotidiano das pessoas principalmente relacionado ao tempo. Assim, o fato de a cidade não existir um restaurante com o fornecimento de comida a quilo, ofereceu subsídio para a oportunidade de um novo negócio.

A empreendedora afirma que nunca procurou um órgão de fomento, nunca fez um curso relacionado a área de restaurante,tampouco cursos específicos de gestão, o que aprendeu foi na Faculdade. A entrevistada menciona que possui uma clientela fixa entre pessoas da comunidade e turistas, destaca que por seu restaurante ser mais "arrumadinho" e com a opção de comida a quilo, único na cidade, o destino é certo. Conta que, um dos pontos essenciais na identificação da oportunidade do negócio foi a organização, pois, acredita que a imagem da empresa seria o principal atrativo para o cliente:

"o diferencial que procurei para o meu restaurante foi a organização, pois a imagem geralmente chama o cliente, principalmente no ramo da alimentação, o pessoal primeiro quer ver uma coisa bonita para depois querer entrar, e percebi que os restaurantes daqui não prezavam por isso"

A forma de identificação da oportunidade, de acordo com a classificação de Chandler, Lyon e Detienne (2005) é do tipo inovar-educar, visto que o processo começou quando a empreendedora introduziu um novo serviço (comida a quilo), que não existia na cidade da empreendedora, e posteriormente mostrou os benefícios que o serviço oferece aos potenciais clientes. No caso da empreendedora E1, o oferecimento de alimentação a quilo representou uma inovação, e em seguida, informou os clientes potenciais sobre os benefícios que o serviço oferecia, conforme verificamos em seu depoimento:

"tive muito trabalho para mudar a cultura das pessoas.As pessoas tinham muito medo do preço, de dar caro, na abertura colocamos um carro de som falando do serviço a quilo, mas mesmo assim foi super difícil, no começo eu praticamente 
paguei pra abrir o restaurante, chegava a ter prejuízo mesmo, vendia muito pouco, mas o prédio alugado e o investimento foram altos, mas tinha certeza que ia conseguir mudar, esse quadro foi difícil. A gente incentivou, pouco a pouco, geralmente pelo boca a boca dos clientes"

Além desse aspecto, a depoente procurou identificar outras possibilidades de inovação para o seu negócio. Um deles estava relacionado com o horário de funcionamento. Segundo a empreendedora, os outros restaurantes da cidade começam a oferecer seus serviços somente após as 11:00h. Assim, a empreendedora decidiu que o seu restaurante funcionaria de segunda a sábado, de 7:00 às 14:30h. Aproveitou essa percepção, para atrair os clientes:

"tinha muita gente que me dizia que precisava almoçar mais cedo mais todos os restaurantes estavam fechados"

\section{A Empreendedora E2}

E2, 35 anos de idade, nasceu em Poço Verde/SE. Seu pai já trabalhou como segurança e também como motorista particular, sua mãe era dona de casa. Segundo a depoente, desde a sua infância já tinha em mente que não queria viver em sua cidade natal. A inserção de E2no empreendedorismo veio muito cedo. Aos doze anos já era proprietária de um pequeno comércio em sua cidade. Aos 14 anos sofreu com a separação de seus pais, no dia em que seu pai saiu de casa ela decidiu mudar-se para Aracaju. Na capital sergipana, o seu primeiro vínculo empregatício foi como empregada doméstica. Por coincidência sua empregadora tinha um salão de beleza. E2 declarou que achava bonito aquele comércio e todo tempo disponível empregava na ajuda ao salão. Ela conta que esta profissão foi sempre seu desejo.

O desejo pelo aprendizado era contínuo e sua empregadora, percebendo o seu interesse e determinação, propôs um acordo: durante a manhã ela se concentraria nos trabalhos domésticos e no período vespertino poderia ir para o salão. E2 prontamente aceitou a proposta segundo relata:

"eu passei a agilizar meus afazeres domésticos para sobrar tempo de ir pro salão aprender. Comecei a lavar cabelos, pranchar e assim fui ganhando espaço, aplicando tintas e hidratações, criei credibilidade com as clientes"

Percebendo o talento da jovem, a empregadora de E2 fez uma nova proposta e a convidou para trabalhar somente no salão, assim o desenho de sua carreira estava iniciado. Ardichvili, Cardozo e Ray (2003) destacam que para identificar uma oportunidade de sucesso o empreendedor deve ter uma convergência de ambos os domínios de conhecimento: 
conhecimento de negócios e conhecimento do setor em que o negócio será criado. Sem essa convergência há uma menor probabilidade de sucesso.

Sobre a sua formação, E2 reconhece o valor, e destaca que mesmo com diversas dificuldades, retomou os estudos e terminou o ensino médio:

"só tenho o segundo grau e terminei através de supletivo. Isso aconteceu porque na área de beleza as pessoas gostam de se arrumar mais tarde e eu nunca tinha tempo de estar na escola no horário certo, mas mesmo assim me interessei e fui terminar o ensino médio"

A trajetória de vida de E2 constata uma larga experiência do setor do negócio que viria a ser criado, o que, segundo Short et al (2010), representa um cenário ideal para identificação de oportunidades. $\mathrm{O}$ conhecimento relacionado à administração do negócio foi conquistado apenas no cotidiano da atividade:

"eu nunca fiz curso na área de gestão, fiz alguns cursos na área de beleza, o comércio nasceu na raça. Também, para o que fazia não necessitava, eu amo o que faço".

Durante sete anos atuou como auxiliar de cabeleireira e depiladora. Contudo, conta que sempre preferiu trabalhar com cabelo, a depilação serviu como forma de aumentar seu rendimento mensal. Seguiu a busca de aperfeiçoamento e começou a fazer cursos específicos da área de estética, E2 conta que seus serviços eram cada vez mais requisitados:

"o meu trabalho já era reconhecido pelas clientes, eu era muito requisitada. Nesse momento eu já era cabeleireira e procurei me aperfeiçoar, fui fazer cursos, comecei a fazer outros trabalhos, já escovar, cortar, aplicar químicas e de $\mathrm{R} \$ 800,00$ meu salário passou pra $\mathrm{R} \$ 1.400,00$ "

E2 relata que conseguiu que sua irmã fosse trabalhar em outro salão de beleza em um bairro nobre de Aracaju. A proprietária do salão decidiu sair do local e sua irmã propôs que elas ficassem com o imóvel, com o intuito de abrir uma loja de peças íntimas, E2 aceitou a proposta, abriu o negócio com a sua irmã, mas continuou trabalhando no salão de beleza, que era o que lhe dava prazer. Segundo a depoente o seu desejo era abrir um salão de beleza, confirmando a relação entre a experiência anterior e o ramo escolhido, apontado por Machado et al (2003). Segundo os autores, há uma tendência que as mulheres identifiquem oportunidades no ramo que estão inseridas ou que atuavam anteriormente.

Apesar de ainda estar satisfeita com o trabalho, a empreendedora, com a ajuda de sua irmã, identificou a oportunidade de abertura de seu próprio negócio, um salão "diferenciado", conforme diz. Esse fato é apontado por Detienne e Chandler (2007) ao afirmarem que as 
mulheres tem mais probabilidade que os homens de apresentar algum diferencial (inovação) em seus negócios em relação as empresas que atuaram. E2viu nos problemas apresentados pelos clientes a oportunidade de criação do seu próprio empreendimento:

"quando fui abrir o meu salão eu procurei trabalhar em cima do que as clientes reclamavam do salão onde eu trabalhava, segundo elas não tinha um salão mais chique em Aracaju. Assim ao criar o meu salão, procurei colocar umas cadeiras melhores, uns produtos de melhor qualidade, servir um cappuccino, hoje eu tenho manobrista, os clientes não se preocupam com vaga de estacionamento, pois o cliente gosta de luxo e sofisticação. Outra coisa que eu primo é pelo horário marcado, pois o cliente não gosta de ficar esperando e isso é o que mais gera insatisfação nos salões"

O depoimento da empreendedora reflete a forma de identificação da oportunidade que está relacionada com o processo aprender-replicar, previsto por Chandler, Lyon e Detienne (2005). A empreendedora identifica a demanda do mercado não atendida e replica o serviço para um mercado que julga carente. No entanto, procura, assim como concluíram Detienne e Chandler (2007), apresentar alguma inovação em relação a sua ocupação anterior, principalmente o que diz respeito ao que não estava sendo adequadamente atendida pelas empresas existentes no mercado. Assim, verifica-se que o conhecimento prévio dos problemas dos clientes aumenta a probabilidade de identificação de oportunidades de sucesso empresarial, conforme afirma Ardichvili, Cardozo e Ray (2003).

Ibarra (1997) destaca, possuir uma rede de relacionamentos ampla e diversificada facilita o processo de identificação de oportunidades. E2 relata que tinha uma rede de contatos ampla, proporcionada principalmente pela sua área de atuação, contrariando a tendência apontada por Vale, Serafim e Teodósio (2011) das mulheres serem mais sensíveis à influência de terceiros no que diz respeito ao desenvolvimento de uma oportunidade identificada, conforme relata:

"Eu tinha muitos contatos, na época de abrir o salão eu consultei uma cliente, eu comentei com ela que tinha visto a possibilidade de abrir um salão mais chique, ela informou que o marido dela era economista, e ia consultá-lo aí ela fez os cálculos todos com ele e disse que era viável, me direcionando em alguns aspectos. Eu tive ela pra me orientar nos custos, nos gastos"

O negócio progrediu e o espaço ficou pequeno e foi necessário mudar-se para um local mais amplo. E2 conta que viu em um de jornal anúncio de uma casa no bairro 13 de Julho e entrou em contato com o corretor, por coincidência a dona do imóvel era sua cliente, esta por conhecer a sua história e de sua irmã, ofereceu um bom desconto, em menos de 3 anos quitaram o imóvel. A clientela foi se consolidando, a empreendedora tem orgulho em dizer 
que a primeira cliente que pisou em seu salão ainda o frequenta.E2 detalha a dificuldade em trabalhar com muitos funcionários, principalmente em seu meio profissional, pois, os cabeleireiros ficam passando por vários salões e com eles os clientes vão, afirma:

"como sabemos o cabeleireiro acaba criando cliente pra ele e não para a empresa, não é para a empresa, então muitos utilizam da boa estrutura do salão apenas para criar clientela, e quando eles saem os clientes também vão, então eles usam e fazem a gente perder dinheiro, eu mesmo perdi 3 funcionários que fizeram meu faturamento baixar entre 14 a 16 mil, então é muito difícil, não é fácil”

Os clientes, para E2, representam a principal fonte de oportunidade. Por solicitação destes, criou um espaço preparado para as noivas, que no dia do casamento, não gostavam de ficar no agito do salão. Percebe-se que foi identificada como uma fonte de oportunidade, a mudança dos hábitos de consumo dos clientes.

Ardichvili, Cardozo e Ray (2003) afirmam que os resultados da identificação de oportunidades ao enriquecer a base de conhecimento do empreendedor, aumenta o estado de alerta, levando à identificação de oportunidades de negócios futuros. Esse fato foi identificado na história de E2. A empreendedora conta que identificou a oportunidade de ampliar os serviços oferecidos no salão. Verificava o que era oferecido nos outros salões e inseria em seu empreendimento os serviços que não eram ofertados no mercado. Assim, no salão de Beleza de E2, além dos serviços de cabeleireiro, manicure e maquiagem, surgiram os serviços de podologia, depilação masculina e feminina, dia da noiva e dia do formando. Comprova-se o desenvolvimento contínuo de oportunidades identificadas pela empreendedora, principalmente relacionada à demanda dos clientes.

\section{A Empreendedora E3}

E3, casada, é natural de São Cristóvão/SE, tem dois filhos, seu pai era fazendeiro e a mãe dona de casa.Dos seus irmãos, alguns são caminhoneiros, outros seguiram a profissão do pai.Um das suas irmãs uma é bióloga, outra é funcionária pública e outra professora.

A empreendedora tem o nível medido completo. Relata que fez vestibular, entrou na faculdade, mas não concluiu o curso, resolveu fazer um curso técnico de instrumentação cirúrgica. Após a finalização do curso, trabalhou por dois anos nesta área. Nesse momento, a empreendedora percebeu que não estava feliz e seguiu para a dedicação ao empreendedorismo. 
E3 relata que sempre desejou ter seu próprio negócio. Afirma que não gostou da experiência como empregada e resolveu se dedicar ao comércio. A sua trajetória de vida é mercada por diversas experiências empreendedoras:

"eu casei cedo, quando eu casei não trabalhava em nada, quando eu casei o meu marido tinha um comércio pequenininho, aí foi crescendo, crescendo, crescendo, no início vendia café para os pescadores, almoço para algumas pessoas, fornecia comida, marmita, bolo, empada, salgado, ai a gente tinha espaço pra crescer e foi crescendo. Quando o mercadinho cresceu eu consegui dinheiro para montar outro mercadinho, aí eu fiquei tomando conta de um mercadinho e meu marido tinha outro, e aí ficou disputando os dois sobre preço, eu comecei a fazer propaganda do meu, botei um locutor pra divulgar, principalmente dia de sábado, aí o meu enchia, e o dele ficava vazio, aí eu olhava de cá, meu Deus do céu, o dele ta vazio, eu não posso fazer isso, mas só que eu vendia muito mais aí foi indo, foi indo e voltamos a ter só um comércio, juntamos os dois e fizemos um supermercado grande, era bem mais interessante, pensei: não vou ficar mais disputando com meu marido sobre preço e nós montamos e fizemos um mercado só"

Porém, após a expansão do comércio, o trabalho aumentou e lucro não foi o esperado. Por iniciativa própria, a empreendedora teve a ideia de abrir um canil com serviço de hotel para cachorros, no intuito de ficar mais "despreocupada" e na tentativa de aumentar o seu rendimento. Entretanto, mais uma vez, segundo relata, não acertou na escolha. $\mathrm{O}$ trabalho continuava árduo e o resultado não foi compensador.

Foi nesse momento que a empreendedora resolveu pesquisar em qual tipo de negócio iria investir. A premissa era identificar um ramo que a trouxesse maior flexibilidade e tranquilidade. Essas dois fatores (flexibilidade e tranquilidade) são citados por Machado (1999) e Gomes (2005) como responsáveis pela escolha das mulheres pelo empreendedorismo. E3 conta que na cidade em que reside só havia um local para realização de festas, a empreendedora viu nessa informação uma oportunidade de negócio:

"a ideia para o salão surgiu após a compreensão de que já estava, como se diz, numa certa idade, querendo mais sossego para aproveitar o resto de vida, acreditando que este novo empreendimento fosse mais tranquilo. A percepção da necessidade do salão de eventos foi por conta própria, vi que aqui na cidade só tinha um salão de festas"

Assim, em uma iniciativa de coragem, E3demoliu metade de sua casa, construiu um salão e inaugurou uma casa de festas. Como testes iniciais, promoveu alguns shows. Todavia, não obteve muito sucesso, pois concentrava muito serviço para si, tais como: vendas de mesa, de convites individuais, de bebidas e petiscos. Ademais, relata que não tinha uma certeza de lucro e não tinha possibilidade de realizar toda semana, além disso, os custos eram altos: 
"os bons seresteiros cobram muito caro e a qualidade estava em primeiro lugar e ainda mais se você não contratar um bom seresteiro não vai ter ninguém, então cada seresteiro cobrava dois mil, dois mil e quinhentos reais, aliás vezes eu tinha muito prejuízo devido a esses valores"

Assim, conforme afirma Anokhin, Wincent e Autio (2011), uma demanda não atendida dos clientes gerou novas informações sobre como os seus recursos poderiam ser usados de forma diferenciada, segundo relata:

“o salão mais requisitado daqui pertence a Igreja Católica, então tem muitas restrições como limite de horário e do tipo de música; muitas pessoas comentavam que queria mais liberdade. E aí, no momento que eu promovia as serestas, muitas pessoas me perguntavam por que eu não alugava o salão para aniversários, casamentos... sabe? Pois segundo eles, o investimento é alto nas festas e querem comemorar com liberdade e no outro salão não era possível. Então, com essa necessidade dos clientes, resolvi deixar de promover os shows e comecei alugar o salão. Foi a melhor coisa que fiz"

O conhecimento prévio do problema enfrentado pelos clientes possibilitou a identificação de uma oportunidade de sucesso empresarial. A solicitação para alugar seu salão para eventos, bem como a percepção da necessidade de mais um salão de eventos na cidade, proporcionou a criação do novo serviço. A depoente desenvolveu a oportunidade baseada nas deficiências identificadas pelos clientes na concorrência. A premissa de E3 foi não aplicar muitas regras para que as pessoas ficassem mais tranquilas. Ela frisou que a redução dessas regras era justamente o que seu principal concorrente não tolerava. Seu salão permite que as festas ultrapassassem o período contratado, porém, de acordo com a essência do negócio, ocorria o pagamento de taxas extras, o que não era permitido no outro salão.Reforçou-se a ideia de que a forma de identificação da oportunidade foi, em determinados aspectos, relacionada ao processo aprender-inovar (CHANDLER; LYON; DETIENNE, 2005).

Segundo Ardichvili, Cardozo e Ray (2003), os resultados positivos advindos da identificação bem sucedida de uma oportunidade aumentam o estado de alerta empreendedor para novas oportunidades. No depoimento de E3 é possível identificar a sua propensão a visualizar novas oportunidades:

"os clientes sempre falam que se sentem muito a vontade aqui. Quando eu pergunto como foi, os clientes falam: aqui não é dez não, é mil. E aí eu fico mais empolgada ainda, ouço o que eles querem e fico pensando em mil modificações para o salão" 
Nota-se que o empreendedorismo sempre norteou sua vida. E3 conta que sempre acreditou primordialmente em suas habilidades pessoais e profissionais, baseadas em sua experiência. O conhecimento relacionado à administração do negócio foi conquistado apenas com as práticas vivenciadas na sua larga vida profissional. A empreendedora até tentou exercer outras funções, porém descobriu que não era sua vocação:

"eu cheguei no comércio, eu tinha dezessete anos e estou até hoje. Quando eu chego ali naquele mercado, aí todo mundo fala comigo, todo mundo me chama, todo mundo me conhece, pergunta se eu não vou abrir novamente o mercado, mas eu não tenho vontade, eu quero sossego, já estou de idade, eu quero viajar, dirigir muito que eu adoro, conhecer outros estados é o que eu quero. Ser dona do meu próprio negócio foi o que eu sempre quis, é tanto que fui ser instrumentadora cirúrgica, mas não me adaptei”

\section{CONSIDERAÇÕES FINAIS}

Este trabalho buscou analisar como ocorre o processo de identificação de oportunidades de criação de novos negócios por meio da história de mulheres empreendedoras das cidades Aracaju e São Cristovão, no estado de Sergipe. As entrevistas tiveram o objetivo de conhecer seus históricos pessoais, sua visão de mercado, conhecimento prévio do setor e negócio escolhido. Três mulheres participaram do trabalho. Por meio das ímpares histórias, foi possível perceber que a habilidade de interpessoalidade, em especial relações que antecederam ao empreendimento, teve forte interferência na identificação da oportunidade.

Por meio dos relatos foi possível afirmar várias razões levaram as empreendedoras a desenvolverem o alerta empreendedor com fins de identificar oportunidades de novos negócios: o sucesso do desenvolvimento de uma oportunidade anterior, a visualização de sucessos de terceiros, o histórico familiar e a possibilidade e satisfação de tomar as próprias decisões e decidir os rumos do empreendimento.

A experiência no setor previu o número de oportunidades identificadas pelas mulheres, conforme já analisado por Detienne e Chandler (2007). As empreendedoras citam em suas falas o processo de aprendizado em experiências anteriores como a base para identificação da oportunidade do novo negócio. São mulheres que adaptaram continuamente o aprendizado adquirido no cotidiano em favor do negócio escolhido. Os resultados indicam que, de modo geral, as oportunidades foram identificadas quando as empreendedoras possuíam vínculos 
empregatícios ou eram proprietárias de estabelecimentos que tinham atividades ligadas aos negócios criados posteriormente.

Outra fonte de identificação das oportunidades foi uma demanda não atendida. Os próprios clientes informavam a necessidade de um novo negócio. Essa identificação apesar de não ser fornecida por uma pesquisa de mercado formal, devido às limitações do tamanho dos negócios, tornou-se uma fonte valiosa de informações para as empreendedoras.

Evidenciou-se também que as empreendedoras mantinham uma forte relação com os clientes que as sinalizaram da potencialidade para abertura de novos negócios e/ou ampliação dos serviços oferecidos. Foi constatado ainda que a não satisfação/adaptação às regras dos vínculos empregatícios foram importantes para a identificação das oportunidades de negócio e a escolha pelo empreendedorismo.

O estudo mostrou ainda que a identificação de uma oportunidade é resultado do atendimento de um conjunto condições e não se dá em um momento isolado. Os depoimentos das empreendedoras deixam evidências que é difícil predeterminar quando se tem o momento exato da identificação de uma oportunidade. Foram um conjunto de conhecimentos, informações de diversas fontes que ao longo do tempo foram desenvolvidas na mente das empreendedoras.

Entretanto, evidenciou-se uma intensa participação da família no processo de identificação das oportunidades. Em uma história, a mãe da empreendedora foi essencial para o sucesso da ação. Em outra história verificou-se a participação efetiva da irmã no processo de identificação de oportunidades. Verifica-se assim que identificar uma oportunidade possa não ser um processo exclusivamente individual. Há de ressaltar que, esses resultados obtidos podem ser utilizados para aprofundar futuras pesquisas que busquem revelar o papel da família na identificação da oportunidade.

A partir das histórias, percebeu-se que a intuição, as habilidades interpessoais e o forte apoio familiar são determinantes na identificação das oportunidades de criação e continuidade dos negócios. Entender, pois, essas habilidades e as expectativas dessas mulheres são de extrema importância para fundamentar o direcionamento de políticas específicas que deem subsídios aos negócios identificados, criados e geridos por mulheres empreendedoras. 


\section{REFERÊNCIAS}

AHL, Helene. Why research on women entrepreneurs needs new directions? Entrepreneurship Theory and Practice,, v. 30, n.5, p. 595-621, Setembro 2006.

ALBERTI, V. História oral: a experiência do CPDOC. Rio de Janeiro: Centro de Pesquisa e Documentação de História Contemporânea do Brasil, 1989.

ALBERTI, V. Manual de história oral. 2.ed. rev. e atualizada. Rio de Janeiro: FGV, 2004.

ALBUQUERQUE, Adson da Rocha Pita; TEIXEIRA, Rivanda Meira. O Processo de Identificação e Exploração de Oportunidade Empreendedora com Base no Modelo de Aprendizagem Organizacional 4i. Revista de Ciências da Administração • v. 18, n. 44, p. 25 37, abril 2016

ANOKHIN, S.; WINCENT, J.; AUTIO, E. Operationalizing opportunities in entrepreneurship research: use of data envelopment analysis.Small Business Economics, v. 37, n. 1, p. 39-57, 2011.

ARDICHVILI, A.; CARDOZO, R.; RAY, S. A theory of entrepreneurial opportunity identification and development.Journal of Business Venturing, v. 18, p. 105-123, 2003.

BARDWICK, J.M. Mulher, sociedade, transição: como o feminismo, a liberação sexual e a procura da auto-realização alteram as nossas vidas. São Paulo: DIFEL, 1984.

BARON, R. A.; SHANE. S. A. Empreendedorismo: uma visão do processo. São Paulo: Thomson Learning, 2007.

BIRLEY, S.Female entrepreneurs: Are they really any different? Journal of Small Business Management,v. 27, p. 32-37, 1989.

CHA, M.; BAE, Z. The entrepreneurial journey: from entrepreneurial intent to opportunity realization. Journal of High Technology Management Research, London, v. 21, n. 1, 2010.

CHANDLER, Gaylen N.; LYON, Douglas W.; DETIENNE, Dawn R. Antecedents and expliotation outcomes of opportunity identification processes. In: ACADEMY OF MANAGEMENT PROCEEDINGS. Academy of Management, 2005.

CRAMER, L.; CAPPELle, M. C. A.; ANDRADE, A. L. S.; BRITO, M. J. de. Representações femininas da ação empreendedora: uma análise da trajetória das mulheres no mundo dos negócios. Revista de Empreendedorismo e Gestão de Pequenas Empresas, v. 1, n. 1, 2012.

CRESWELL, J. W. Research design: qualitative, quantitative, and mixed methods approaches. London: Sage, 2003.

DETIENNE, D.; CHANDLER, G.The role of gender in opportunity identification. Entrepreneurship Theory and Practice, v. 31, p. 365-386, 2007. 
DEMARTINI, Z. B. F. História de vida na abordagem de problemas educacionais. In: SIMSON, O. M. V. (Org.) Experimentos em história de vida. Itália - Brasil, São Paulo. Revista dos Tribunais, 1988.

DIMOV, D. Nascent entrepreneurs and venture emergence: Opportunity confidence, human capital, and early planning. Journal of Management Studies, v. 47, n. 6, p. 1123-1153, 2010.

DRUCKER, P. F. Inovação e Espírito Empreendedor - Entrepreneurship. 6. ed.São Paulo: Pioneira, 1985.

ECKHARDT, J.; SHANE, S. Opportunities and entrepreneurship. Journal of Management, v. 29, p. $333-394,2003$.

FARIA, J. H. de. Consciência crítica com ciência idealista: paradoxos da redução sociológica na fenomenologia de Guerreiro Ramos. Cadernos EBAPE.BR, Rio de Janeiro, vol.7, n.3, 2009.

FERREIRA, M. de M.; AMADO, J. (Orgs). Usos e abusos da história oral. 2 ed.- Rio de Janeiro: Editora da Fundação Getúlio Vargas, 1998.

FERREIRA, J. M.; NOGUEIRA, E. E. S. Mulheres e Suas Histórias: Razão, Sensibilidade e Subjetividade no Empreendedorismo Feminino. Revista de Administração Contemporânea, Rio de Janeiro, v. 17, n. 4, 2013.

FILION, L. J.; LIMA, E. As Representações Empreendedoras: Um Tema Essencial, mas ainda Negligenciado. Revista de Negócios, v. 14, n. 2, 2009.

FREITAS, S. M. de. História Oral: Possibilidades e Procedimentos. 2. ed. São Paulo: Associação Editorial Humanitas, 2006.

GLOBAL ENTREPRENEURSHIP MONITOR. Empreendedorismo no Brasil: 2015. Relatório Executivo. Curitiba: Instituto Brasileiro da Qualidade e Produtividade - IBQP/SEBRAE/FGV, 2015.

GLOBAL ENTREPRENEURSHIP MONITOR. Empreendedorismo no Brasil: 2015. Análise dos resultados do GEM 2015 por gênero. Curitiba: Instituto Brasileiro da Qualidade e Produtividade - IBQP/SEBRAE/FGV, 2015.

GOMES, A. F. O Perfil Empreendedor de Mulheres que Conduzem seu Próprio Negócio: um estudo na cidade de Vitória da Conquista-BA. Revista Alcance, v. 11, n. 2, p. 207-226, 2005.

GOMES, A. F.; SANTANA, W. G. P. A história oral na análise organizacional: a possível e promissora conversa entre a história e a administração. Cadernos EBAPE.BR. Rio de Janeiro, v. 8, n. 1, p. 1-18, 2010.

GONZÁLEZ-ÁLVAREZ, N.; SOLÍS-RODRÍGUEZ, V. Descubrimiento de oportunidades empresariales: capital humano, capital social y género. INNOVAR, v. 21, p. 187-196, 2011. 
GRÉGOIRE, D. A.; SHEPHERD, D. A. Technology-market combinations and the identification of entrepreneurial opportunities: An investigation of the opportunity-individual nexus. Academy of Management Journal, v. 55, n. 4, 2012.

GRUBER, M., MACMILLAN, I. C., \& THOMPSON, J. D. Escaping the prior knowledge corridor: What shapes the number and variety of market opportunities identified before market entry of technology startups? Organization Science v. 24, 2013.

GUPTA, Vishal K.; GOKTAN, Banu; GUNAY, Gonca. Gender differences in evaluation of new business opportunity: A stereotype threat perspective. Journal of Business Venturing v.. 29, pp 273-288, 2014.

HISRICH, R. D.; PETERS, M. P. Entrepreneurship.New York: McGraw Hill, 2002.

IBARRA, H. Gender differences in managerial networks. Social Psychology Quarterly, v. 60, p. 91-102, 1997.

JENNINGS; Jennifer E; BRUSH, Candida G. Research on Women Entrepreneurs: Challenges to (and from) the Broader Entrepreneurship Literature? The Academy of Management Annals, 2013, v. 7, n. 1, p. 663-715

GOMES, Almiralva Ferraz ; SANTANA, Weslei Gusmão Piau; ARAÚJO, Uajará Pessoa; MARTINS, Caroline Miriã Fontes. Empreendedorismo Feminino como sujeito de pesquisa. RGBN- R. Bras. Gest. Neg., São Paulo, v. 16, n. 51, p. 319-342, abr./jun. 2014.

JONATHAN, E. G. Mulheres empreendedoras: medos, conquistas e qualidade de vida. Psicologia em Estudo, v. 10, n. 3, p. 373-382, 2005.

KIRZNER, I. Competition and Entrepreneurship. Chicago: Univ.of Chicago Press, 1973.

LEWIS, Kate V.; HO, Marcus; HARRIS; Candice; MORRISON; Rachel. Becoming an entrepreneur: opportunities and identity transitions, International Journal of Gender and Entrepreneurship, v. 8, pp. 98 - 116, 2016.

MACHADO, H. V. Tendências do comportamento gerencial da mulher empreendedora. In: XXIII ENCONTRO DA ASSOCIAÇÃO NACIONAL DE PÓS-GRADUAÇÃO EM ADMINISTRAÇÃO. 23. Foz do Iguaçu. Anais. Foz do Iguaçu: ANPAD, 1999.

MACHADO, H. V.; ST-CYR, L.; MIONE, A.; ALVES, M. C. M. O Processo de Criação de Empresas por Mulheres. RAE-eletrônica, v.2, n.2, 2003.

MEIHY, José Carlos S. B. Manual de história oral. 4. ed. São Paulo: Loyola, 2002.

MENZIES, T. V.; DIOCHON, M.; GASSE, Y. Examining venture-related myths concerning women entrepreneurs. Journal of Developmental Entrepreneurship, v. 9, n. 2, 2004.

OCDE: Relatory Gender Equality in Education, Employment and Entrepreneurship. Meeting of the OECD Council at Ministerial Level: Paris, 2012. 
RUTASHOBYA, L. K; ALLAN, I. S; NILSSON, K. Networks, social relationships andentrepreneurial outcomes in Tanzania. Journal of African Business, v. 10 n. 1, 2009.

SHANE, S. Prior knowledge and the discovery of entrepreneurial opportunities. .Organization Science, v. 11, 2000.

SHANE, S.; NICOLAOU, N. Creative personality, opportunity recognition and the tendency to start businesses: A study of their genetic predispositions Journal of Business Venturing v. 30, p. 407-419, 2015.

SHANE, S.; VENKATARAMAN, S.The promise of entrepreneurship as a field of research. Academy of Management Review, v. 25, n. 1, 2000.

SHOOK, C. L.; PRIEM, R. L.; MCGEE, J. E. Venture creation and the enterprising individual.Journal of Management, v. 29 n. 3, 2003.

SHORT, J. C; KETCHEN, D. J.; SHOOK, C. L.; IRELAND, R. D. The concept of "opportunity" in entrepreneurship research: Past accomplishments and future challenges. Journal of Management, v. 36, n. 1, p. 40-65, 2010.

SMITH, R. Masculinity, doxa and the institutionalisation of entrepreneurial identity in the novel Cityboy. International Journal of Gender and Entrepreneurship, v. 2, n. 1, p. 2748, 2010.

UCBASARAN, D.; WESTHEAD, P.; WRIGHT, M. The extent and nature of opportunity identification by experienced entrepreneurs. Journal of Business Venturing, v. 24, n. 2, p. 99-115, 2009.

VALE,G. M.; SERAFIN, A.C.F.; TEODÓSIO, A.C.F. Gênero, Imersão e Empreendedorismo: Sexo Frágil, Laços Fortes? RAC, Curitiba, v. 15, n. 4, Jul./Ago. 2011

VERGARA, S. C. Projetos e relatórios de pesquisa em administração, 7. ed. São Paulo: Atlas, 2006.

VENKATARAMAN, S. The distinctive domain of entrepreneurship research: An editor's perspective. In KATZJ.; BROCKHAUS R. (Eds.), Advances in entrepreneurship, firm emergence and growth. V. 3, p. 119-138. Greenwich, CT: JAI Press, 1997.

WOOD, Matthew S.; McKELVIE, Alexander; HAYNIE, J. Michael. Making it personal: Opportunity individuation and the shaping of opportunity beliefs. Journal of Business Venturing , v. 29, p. 252-272, 2014

YETIM, N. Social capital in female entrepreneurship. International Sociology, v. 23 n. 6, 2008. 